\section{Podophyllin for Warts}

Q.-What is known of the treatment of warts by podophyllin? Please supply references if possible.

A.-Treatment of warts by podophyllin was described by Culp, O. S., Magid, M. A., and Kaplan, I. W., J. Urol., 1944, 51, 655; and MacGregor, J. V., B.M.J., 1945, 1, 593. A $25 \%$ suspension in mineral oil or a paste made with podophyllin and water is applied to penile, vulval, or anal warts or warts in other moist sites, for a period of six hours and is then washed off. Occasionally more than one application is necessary. In these sites the warts dry and drop off within a few days. Podophyllin is an irritant, but is rarely an effective measure except for the type of wart found in moist sites.

\section{Prognosis after Splenectomy}

0.-What advice and prognosis should be given to an otherwise healthy young man who has had a splenectomy owing to rupture as a result of injury?

A.-Resistance to protozoan infections such as malaria is believed to be reduced by splenectomy. The patient should, therefore, be advised not to visit the Tropics, but apart from this no precautions are needed and the expectation of life and health is normal.

\section{Terminating Pregnancy}

Q. $-A$ married woman is suffering from severe pulmonary tuberculosis and also showing signs of myocardial degeneration. She has become pregnant, and I could have her curetted, but that inrolves the risk of an anaesthetic. 'Would it be possible to terminate her pregnancy by means of a glandular preparation-e.g., stilboestrol? If so, what would be the best method of administration and dosage?

A. - When the foetus is dead but retained in utero, stilboestrol and other oestrogens, if given regularly over the course of 5 to 8 days, usually sensitize the uterine musculature to such an extent that expulsion of the products of conception occurs. If, however, as in this case, the pregnancy is alive, oestrogens, even in massive doses, do not produce abortion except on rare occasions when the patient is perhaps unusually sensitive. The same applies to the use of strong purgatives, quinine, ergot preparations, pituitary extracts, etc. Although the possibility of this patient or her uterus being susceptible might make some kind of medical induction worth trying, it is unlikely to be successful, and some form of operative interference will probably be required. The anaesthetic risk would be reduced to a minimum by the employment of a skilled anaesthetist, to whom the choice of anaesthetic should be left. Alternatively, it is possible to carry out dilatation of the cervix and to insert a pack or laminaria tents or even to evacuate the uterus, after infiltration of the cervix and the broad ligaments with a local analgesic. But if the condi:ion of this patient is so grave as to warrant induction of abortion, there is much to be said for sterilization at the same time. In that case there can be little doubt that the ideal treatment would be to carry out abdominal hysterotomy and sterilization under local analgesia-a technique which is not difficult.

\section{INCOME TAX}

\section{Expenses: Life Assurance Allowance}

J. K. inquires (a) whether he can claim as an expense the fee of f5 1s. paid to the General Medical Council for original registration, and $(b)$ whether the restriction of the life assurance allowance to one-sixth of the income is determined by gross income or gross income less allowable expenses.

${ }_{*}^{*}(a)$ The fee in question would appear to be paid in order that the practitioner may exercise his profession rather than incurred in the course of his work. We think that the. Revenue authorities might successfully contend that this particular payment was of a capital nature and therefore not allowable. (b) The phrase used in the statute is " one-sixth of the total income of the person from all sources estimated in accordance with the provisions of the Income Tax Acts." The earned income must therefore be taken at the assessable amount-i.e., the expenses must be deducted.

\section{Locumtenent}

T. L. states that most of his income is derived from work as locumtenent and that he is assessed on his annual earnings and not dealt with under the "pay-as-you-earn" system. Can he claim to deduct the expense of travelling between his residence and the places where he does locumtenent work?

*** If, as we gather, the changes in the locumtenencies are sufficiently frequent to justify $T$. $L$. in being regarded not as the employee of various practitioners from time to time but as carrying on his profession in a particular manner, then in our view he is assessable under Schedule D and not under Schedule E. If so, he should be regarded as carrying on his profession from his residence as the centre, and the expense of travelling should be allowed.

\section{LETTERS, NOTES, ETC.}

Breast-feeding of Infants

Lieut.-Col. W. E. C. LunN-RockLifFe, R.A.M.C.(ret.), writes: In a recently published book, The Farming Ladder, by George Henderson, I came across the following passage (page 68): "I once. had the pleasure of studying some records kept by a farmer in $\overrightarrow{\vec{F}}$ Northern Ireland over many years, which showed conclusively that for production and longevity the cows which had been reared on? two outlying small farms, with ample milk available, had far sur-음 passed those reared under the farmer's own careful supervision on $\overline{\bar{c}}$ calf meal, where he was in a position to retail every pint of milk $\overrightarrow{\mathbb{D}}$ produced, and had therefore been misled into believing that calf- $\varrho$ rearing with meal was more economical. It is useful in changing? over from milk, and we use it, but we still believe that the cow will return a hundredfold the milk she received as a calf, or will with- $\vec{O}$ hold in proportion that part of her birthright of which she has beenrobbed, through the reduction in health and vitality resulting from it. It is not what a calf looks like at six months old that matters, $\mathcal{O}$ it is how much milk she will be giving at six years old or later."을 If this is true of cattle may it not also apply to human beings, and 3 . explain to a certain extent the difficulty modern mothers appear toin have in providing sufficient breast milk for their infants? Possibly their own mothers for some reason denied them their full quota of breast milk; hence the vicious circle.

Fish-bone embedded in Tonsil, Simulating Neoplasm

Mr. A. J. D'AbreU, M.B., F.R.C.S.Ed., writes from Newtown, 은 Waterford: In January, 1926, a woman aged 61 consulted me forN pain in her throat, shooting up towards her right ear, and slight $\checkmark$ dysphagia. She gave a history of swallowing a fish-bone a yearo ago, which she thought had stuck in her throat. She attended? hospital in Swansea; no fish-bone was discovered, and she waso treated with gargles, making repeated attendances at the hospital. On examination I found that the right tonsil was swollen and pro- $\rightarrow$ jected much beyond the pillars; I could see a slough on it. There was a small gland at the angle of the jaw. The tonsil felt hard oncr palpation, and yet it was not the hardness of a carcinomatous tonsil. The diagnosis was in doubt. Under regional analgesia the wholeo tonsil in the lingual prolongation, and the posterior pillar which appeared to be involved, were excised and " hemaplastin " injected around and into the tonsillar fossa. There was no post-operativen bleeding, and the throat healed in due course of time with complete disappearance of symptoms. The whole mass was sent to the pathologist, whose report stated that there was no malignancy, that the tonsil was myxomatous, and that in its centre there was a fish- 3 bone.

\section{Bart's in the War}

The Treasurer's latest report of St. Bartholomew's Hospital opens with these words: "Although this report is intended primarily to cover the activities of the hospital in 1944, I cannot put off till nex year all reference to the vital events of the early part of $1945^{2}$ culminating in the cessation of hostilities in Europe. For five and a half grim and tragic years our ancient hospital, standing in the heart of the City, battered and shaken by bombs and fire and rockets, has proudly carried on, without a break, its task of succouring the sick $\bar{\not}$ the wounded, and the suffering. Never once during all that time were its doors closed. Often there was no water, no gas, no light? But still the hospital carried on. We are entitled to be proud of our record of over eight centuries of service, but never during its long history has Bart's added more lustre to its name, or earnefo more affection and regard, than during these years of war. The Governors are deeply conscious of the debt they owe to the medicalin nursing, and lay staffs, whose untiring and devoted labours were sq wholly in keeping with our ancient traditions and enabled thew hospital to retain its record of continuous service unimpaired. WO look forward now to brighter times ahead, but they are times which will be fraught with difficulties and problems allowing of no easing up of our efforts.'

\section{Disclaimer}

Dr. G. Roche LYNCH (St. Mary's Hospital, Paddington) writes: Please allow me to inform your readers that $I$ was in no way responsible for communicating to a reporter any statement to the effect that Her Majesty the Queen had at any time visited mxD laboratory. The article which has caused me serious misgivings appeared in the Daily Express for Wednesday, Oct. 17, 1945, and was entitled "Just near Paddington Station." Steps have been taken to register a strong protest with the editor of the newspaper concernedo pointing out the erroneous statements that have appeared in the article.

\section{Correction}

There was a mistake in the fifth line of paragraph 3 of Major H. L. Thornton's note on "Wide-bore Endotracheal Connexions" (Oct. 20, p. 534). The internal diameter of the distal end is $1.7 \mathrm{~cm}$. not 7.5. 